Monatsschrift f. Geburtshülfe u. Gynäkologie 1918;47:280

\title{
Die Deutschen Frauenkliniken im siebenten Kriegssemester
}

\section{(Nachtrag.)}

Freiburg. Die Klinik ist in vollem ümfange aufrecht erhalten. Naeh dem Tode des Direktors Geheimrat Krönig am 29. X. 1917 werden die Direktorialgeschäfte I is zur Neuberufung von dem derzeitigen Dekan geftihrt, die Klinik wird im übrigen von Privatdozent Dr. P. W Siegel geführt. Aus dem Felde sind keine Assistenten zurückgekeYi t A wsend sind von Assistenten heute: Priv.-Doz. Dr. P. W. Siegel, Dr. Müller-Carioba, Dr. Mitscherlich, Dr. Dreyer und wissensehafthcher Assistent Priv.-Doz. für Physik Dr. W. Friedńch.

Zahl der Zuhörer in der geburtshülflich-gynäkologischen Klinik ungefähr 50, meist Kriegsteilriehmer.

Die Geburtenzahl der Klinik ist von 1250 auf 900 gesunken, die Zahl der po iklinischen geburtshülflichen Fälle ist auf die Hälfte reduziert. Die Abortzahl ist unverändert. Das gynäkologische Material ist ebenfalls unverändert. 